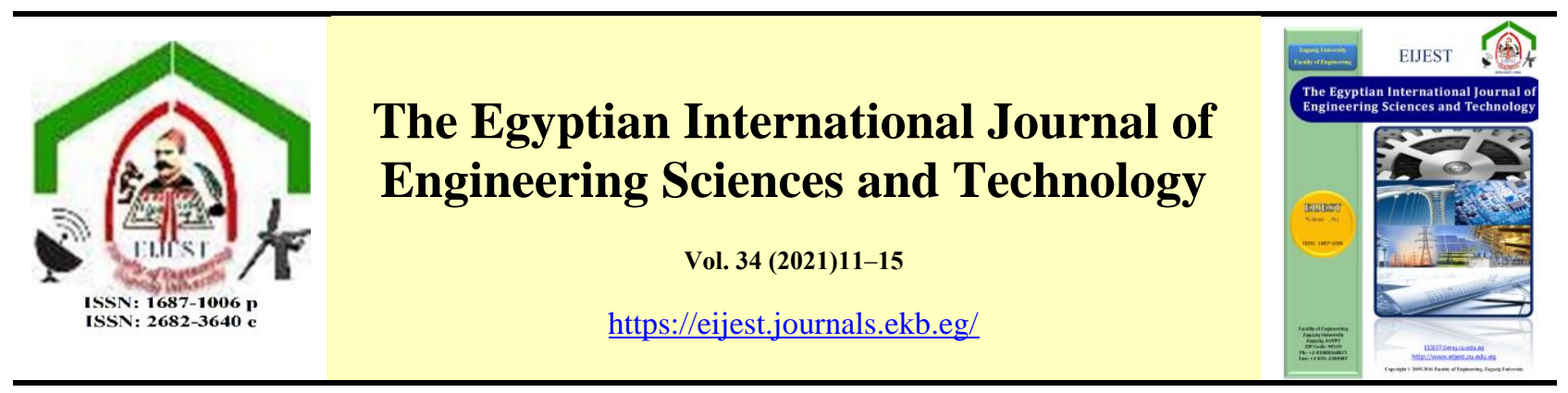

\title{
Distinctive Features of River Sand, Beach Sand and Granite as Adsorbents in Water and Wastewater Treatment
}

\author{
Ayokunle O. Familusi ${ }^{\mathrm{a} *}$, Adebola A. Adekunle ${ }^{\mathrm{a}}$, Adedayo A. Badejo ${ }^{\mathrm{a}}$, \\ Olayemi J. Adeosun ${ }^{\mathrm{b}}$ \\ ${ }^{a}$ Department of Civil Engineering, Federal University of Agriculture, Abeokuta, Nigeria \\ ${ }^{b}$ Department of Agricultural and Bio-Systems Engineering, Federal University of Agriculture, Abeokuta, Nigeria
}

\section{A R T I CL E I N F O}

\section{Keywords:}

Adsorbent

Sand

EDX Analysis

SEM Analysis

XRF Analysis

\begin{abstract}
A B S T R A C T
The essence of adsorbents in water or wastewater treatment cannot be estimated. This research paper seeks to investigate the characterisation of river sand, beach sand and granite as adsorbents for water or wastewater treatment. River sand, beach sand and granite (collected in some localities in Nigeria) were sieved, washed and later sun-dried. These three materials were taken to the laboratory for X-ray Fluorescence Analysis (XRF), Scanning Electron Microscope (SEM) and Energy Dispersive X-ray (EDX) analyses. The XRF analysis revealed that the oxides present in the selected materials include Silica $\left(\mathrm{SiO}_{2}\right)$, Alumina $\left(\mathrm{AI}_{2} \mathrm{O}_{3}\right)$, Ferric Oxide $\left(\mathrm{Fe}_{2} \mathrm{O}_{3}\right)$, Titanium Oxide $\left(\mathrm{TiO}_{2}\right)$, Calcium Oxide $(\mathrm{CaO})$, some other oxides and trace elements like Barium, Copper, Chromium, Nickel, and so on. The SEM analysis shows that the materials possess interconnected pores, while the EDX analysis of the adsorbent materials revealed that the materials contain Silicon, Oxygen, Aluminium, Carbon and other elements. These distinctive features in the selected materials make them excellent materials for water or wastewater treatment.
\end{abstract}

\section{Introduction}

Adsorbents have been found to be of great importance in water and waste water treatment and according to [1], major types of adsorbents in use are activated alumina, silica gel, activated carbon, molecular sieve carbon, molecular sieve zeolites and polymeric adsorbents. Pore sizes in these adsorbents may be distributed throughout the solid, and are classified generally into three ranges, which include macropores having "diameters" in excess of 50-nm, mesopores (also known as transitional pores) having "diameters" in the range of 2 - 50-nm, and micropores having "diameters" which are smaller than 2-nm. Typical characteristics of an adsorbent [2] include high thermal stability, small pore diameters, high exposed surface area (and hence high surface capacity for adsorption), and distinct pore structure (which enables fast mass transport). It was also affirmed in the work of [3] that possession of larger proportion of Silica, Carbon, and more pores are typical features of a good adsorbent in water or waste water treatment. Moreover, most industrial adsorbents fall into any of the three categories, viz. oxygen-containing compounds, polymer-based compounds and carbon-based compounds. Filter aggregates generally consist of sand, gravel or

*Corresponding author. Tel.: +234-806-206-0756

E-mail address: ayomacfamilson@gmail.com 
crushed rock [4]. Sand, which is ubiquitous, has been used as an adsorbent because of its enormous availability in the local environment. Different types of sand, which are available in bulk, have a considerable adsorption capacity for anionic, cationic and nonionic dye removal. Consequently, the usage of different types of sand in the field of adsorption science represents a viable and powerful tool, resulting into the superior improvement in pollution control and environmental preservation [5]. Sand can filter out particles as small as 25 microns [6]. Clay minerals [7] which are important constituents of soil play the role of natural scavengers for metals as water flows over or through soils. It was further concluded by [7] that the riverbed sand, an abundant low cost adsorbent, can be used for removal of heavy metals from aqueous solutions and wastewater as the cation exchange capacity of the adsorbent determined from the work confirms riverbed sand as a suitable material for heavy metal removal from waters rich in metallic species, while [8] submitted in their work that Lawrencepur sand can also be used as low cost adsorbent for removal of Cr (VI) from waste water. Atimes, sand media [9] can be treated through chemical means in order to remove some specific deposits and make the media suitable for water treatment. The thrust of this research work is to evaluate the features of river sand, beach sand and granite as adsorbents in water or wastewater treatment.

\section{Materials and Methods}

\subsection{Materials and Equipment Required for the Study}

The materials and equipment used in carrying out this research work include:

- Granite (of sizes 0-37.5mm)

- Beach Sand (of nominal size 1mm)

- River Sand (of nominal size $1 \mathrm{~mm}$ )

- Set of BS Sieves

- Mechanical Sieve Shaker

- The X-ray Fluorescence (XRF) analysis equipment

- The Scanning Electron Microscope (SEM)/Energy Dispersive X-ray (EDX) analysis equipment

\subsection{Methods}

\section{Sample Preparation}

The river sand (collected at Ede, Nigeria), was sieved (to obtain a nominal size of $1 \mathrm{~mm}$ ), washed and later sun-dried. Likewise, beach sand (collected at Lagos, Nigeria), was sieved (to obtain a nominal size of $1 \mathrm{~mm}$ ), washed and later sun-dried while the granite (collected from a quarry in Awo, Nigeria) used was sieved (through a set of BS sieves 0$37.5 \mathrm{~mm}$ with the aid of mechanical sieve shaker), washed and later sundried. These three materials were later taken to the laboratory for XRF, SEM and EDX analyses.

\section{XRF Analysis}

XRF analysis was carried out on the sample of river sand in line with the procedure highlighted by [3]. The whole XRF process was also repeated for samples of beach sand and granite.

\section{SEM and EDX Analyses}

Likewise, the SEM and EDX analyses were carried out on the sample of river sand in line with the procedure highlighted by [3]. The whole SEM and EDX processes were also repeated for samples of beach sand and granite.

\section{Results and Discussion}

\section{Sieve Analysis of the Granite Used}

The particle size distribution of the granite used is shown in Figure 1 and it could be deduced that $87 \%$ of the granite used is greater than $2 \mathrm{~mm}$.

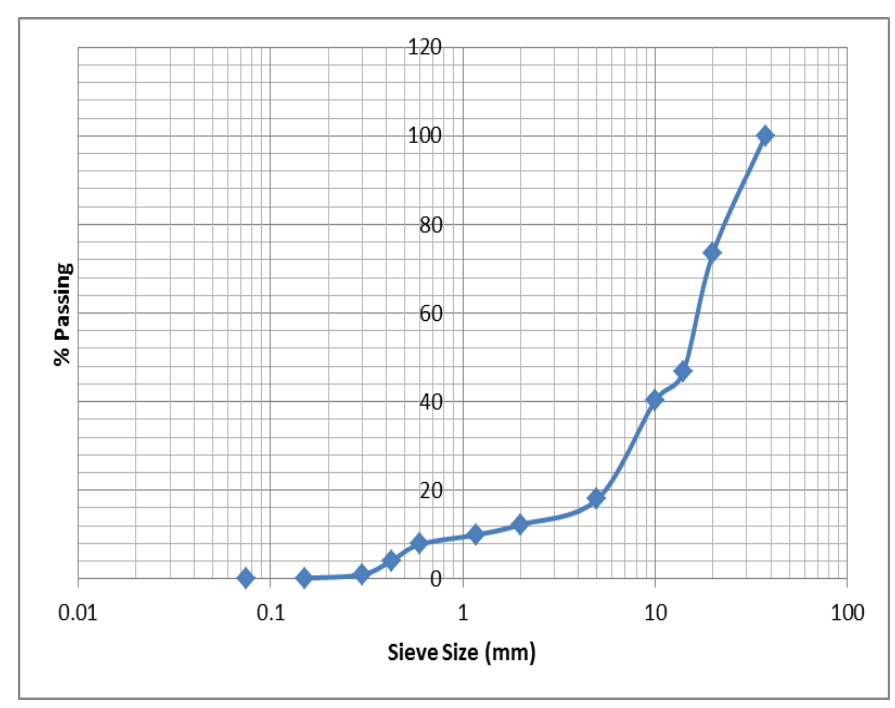

Fig. 1: Particle Size Distribution of Granite Used

From equation 1, the Coefficient of Curvature $\left(\mathrm{C}_{\mathrm{c}}\right)$ is 2.083 , hence it can be concluded that the granite used is well graded (since $\mathrm{C}_{\mathrm{c}}$ is between 1 and 3 ). Similarly from equation 2 , Uniformity Coefficient $\left(\mathrm{C}_{\mathrm{u}}\right)$ was found to be 12 which is greater than the limit 6, this also affirms that the granite is well graded. 
From Figure 1: $\mathrm{D}_{10}=1.5 \mathrm{~mm}, \mathrm{D}_{30}=7.5 \mathrm{~mm}$ and $\mathrm{D}_{60}=18 \mathrm{~mm}$

Coefficient of Curvature $\left(\mathrm{C}_{\mathrm{c}}\right)=\frac{\left(\mathrm{D}_{80}\right)^{2}}{\mathrm{D}_{60} \times \mathrm{D}_{10}}$.

$$
\mathrm{Cc}=\frac{7.5^{2}}{18 \times 1.5}=2.083
$$

$$
\begin{aligned}
& \text { Uniformity Coefficient }\left(C_{u}\right)=\frac{D_{60}}{D_{10}} \ldots \\
& \qquad \mathrm{Cu}=\frac{18}{1.5}=12
\end{aligned}
$$

\section{XRF Analysis}

The results obtained from XRF analysis of the adsorbents are shown in Tables 1 and 2. The oxides present in the filter materials (as shown in Table 1) include Silica $\left(\mathrm{SiO}_{2}\right)$, Alumina $\left(\mathrm{AI}_{2} \mathrm{O}_{3}\right)$, Ferric Oxide $\left(\mathrm{Fe}_{2} \mathrm{O}_{3}\right)$, Titanium Oxide $\left(\mathrm{TiO}_{2}\right)$, Calcium Oxide $(\mathrm{CaO})$, Potassium Oxide $\left(\mathrm{K}_{2} \mathrm{O}\right)$, Manganese Oxide $(\mathrm{MnO})$, Magnesium Oxide $(\mathrm{MgO})$ and Sodium Oxide $\left(\mathrm{Na}_{2} \mathrm{O}\right)$. Loss on ignition of less than $1 \%$ was noticeable in all the selected materials and this suggests that the composition of hydrates and volatile materials in the materials is very minute. Diphosphorus pentoxide $\left(\mathrm{P}_{2} \mathrm{O}_{5}\right)$ was present in minute quantity in the river sand and granite, but was totally absent in the beach sand. The trace metals found in the three materials include Barium, Copper, Chromium, Nickel, Zinc, Cobalt, Strontium, Lead, Scandium and Cadmium. Niobium, Zirconium and Rubidium were present in granite only, but were absent in the other two materials.

Table 1: XRF Analysis Showing Concentration of Oxides in the Filter Materials

\begin{tabular}{llll}
\hline \multirow{2}{*}{$\begin{array}{l}\text { Major } \\
\text { Oxides }\end{array}$} & \multicolumn{3}{c}{ Concentration (Wt \%) } \\
\cline { 2 - 4 } $\mathrm{SiO}_{2}$ & River Sand & Beach Sand & Granite \\
$\mathrm{AI}_{2} \mathrm{O}_{3}$ & 29.46 & 56.39 & 68.13 \\
$\mathrm{Fe}_{2} \mathrm{O}_{3}$ & 4.02 & 24.60 & 13.54 \\
$\mathrm{TiO}_{2}$ & 1.25 & 4.66 & 3.16 \\
$\mathrm{CaO}$ & 1.75 & 1.13 & 0.81 \\
$\mathrm{P}_{2} \mathrm{O}_{5}$ & 0.04 & 1.66 & 1.74 \\
$\mathrm{~K}_{2} \mathrm{O}$ & 0.98 & - & 0.29 \\
$\mathrm{MnO}$ & 0.08 & 0.89 & 3.48 \\
$\mathrm{MgO}$ & 4.75 & 0.07 & 0.22 \\
$\mathrm{Na}$ & 0.90 & 6.69 & 0.14 \\
$\mathrm{LOI}$ & 0.02 & 0.04 & 2.50 \\
\hline
\end{tabular}

Table 2: XRF Analysis Showing Concentration of Trace Metals in the Filter Materials

\begin{tabular}{llll}
\hline Trace & \multicolumn{3}{c}{ Concentration $(\mathrm{Ppm})$} \\
\cline { 2 - 4 } Elements & River Sand & Beach Sand & Granite \\
\hline $\mathrm{Ba}$ & 862.62 & 990.61 & 1141 \\
$\mathrm{Cu}$ & 21.31 & 23.30 & 158 \\
$\mathrm{Cr}$ & 48.20 & 22.40 & 171 \\
$\mathrm{Ni}$ & 10.40 & 21.52 & 83 \\
$\mathrm{Zn}$ & 40.45 & 10.42 & 120 \\
$\mathrm{Co}$ & 11.30 & 12.18 & 46 \\
$\mathrm{Sr}$ & 42.11 & 10.00 & 189 \\
$\mathrm{~Pb}$ & 20.30 & 20.45 & 11 \\
$\mathrm{Sc}$ & 8.15 & 30.25 & 90 \\
$\mathrm{Cd}$ & 0.08 & 0.21 & 11 \\
$\mathrm{Nb}$ & - & - & 35 \\
$\mathrm{Rb}$ & - & - & 10 \\
$\mathrm{Zr}$ & - & - & 189 \\
\hline
\end{tabular}

\section{SEM Analysis}

The results obtained from SEM analysis shown in Figures 2, 3 and 4 at the magnification of 8,000 times revealed that several interconnected pores were noticeable in the selected materials. Bigger pores were noticed in the granite (as shown in Figure 4) and the adsorbent size (of the granite) is bigger, while smaller pores were found in the beach sand (shown in Figure 3) and the river sand (shown in Figure 2) and the adsorbent size is smaller. It was submitted by [10] that the smaller the filter pores, the more contaminants the filter can remove. This suggests that both the beach sand and river sand will serve as better adsorbents than granite.

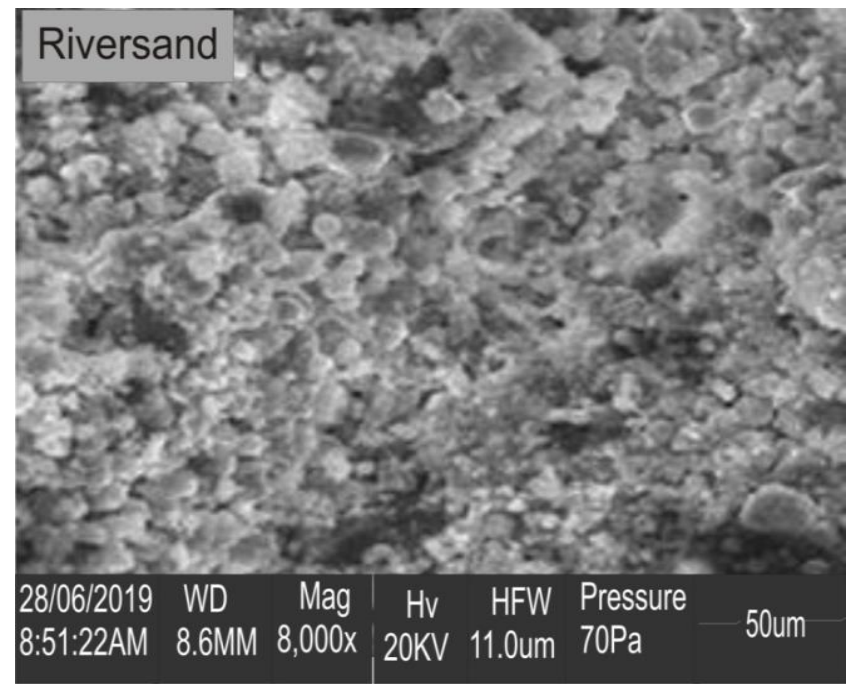

Fig. 2: SEM Analysis Showing Surface Morphology of the River Sand 


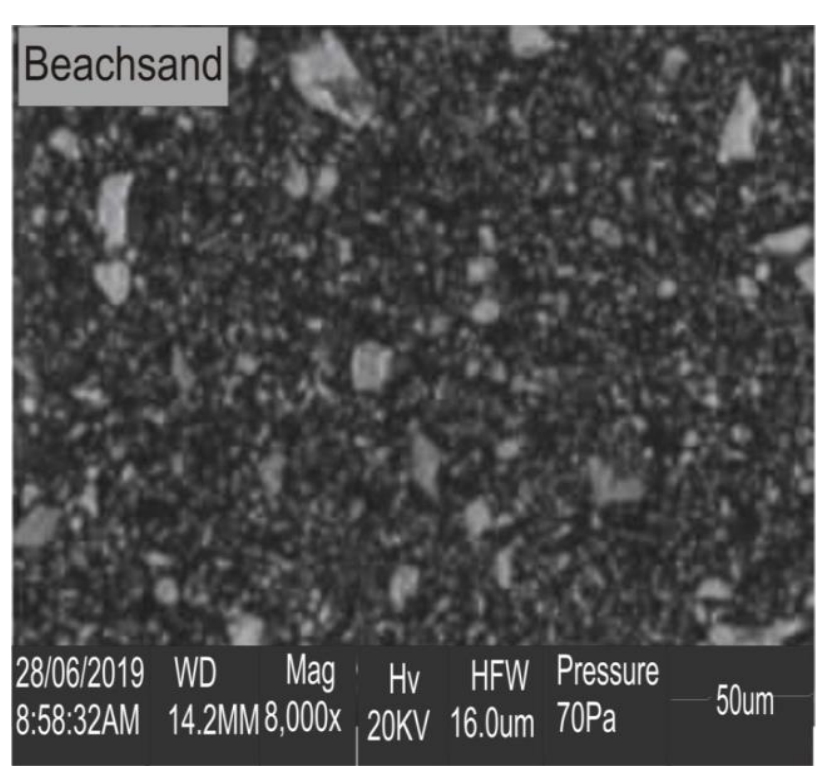

Fig. 3: SEM Analysis Showing Surface Morphology of the Beach Sand

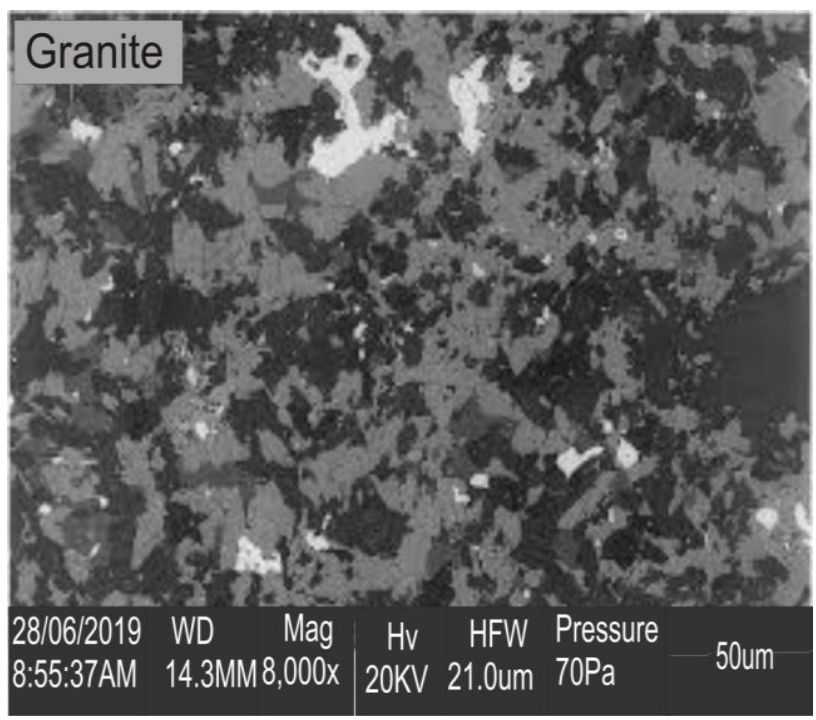

Fig. 4: SEM Analysis Showing Surface Morphology of the Granite

\section{EDX Analysis}

The EDX analysis of the adsorbent materials shown in Figures 5, 6 and 7 revealed that the selected materials contain Silicon, Oxygen, Aluminium, Carbon, Iron, Sodium, Calcium and Potassium. Magnesium was present in minute quantity in the river sand (shown in Figure 5) and granite (shown in Figure 7), but was absent in the beach sand (shown in Figure 6), that suggests that one of the probabilities of water hardness that would have resulted from the filter materials has been minimised. Silicon happened to be principal element in all the selected materials.

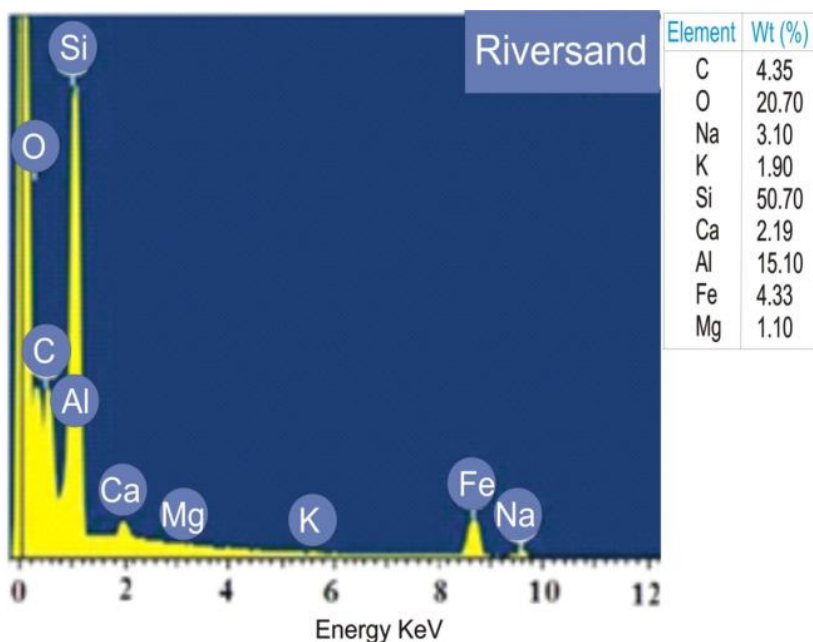

Fig. 5: EDX Analysis Showing Chemical Characterisation of the River Sand

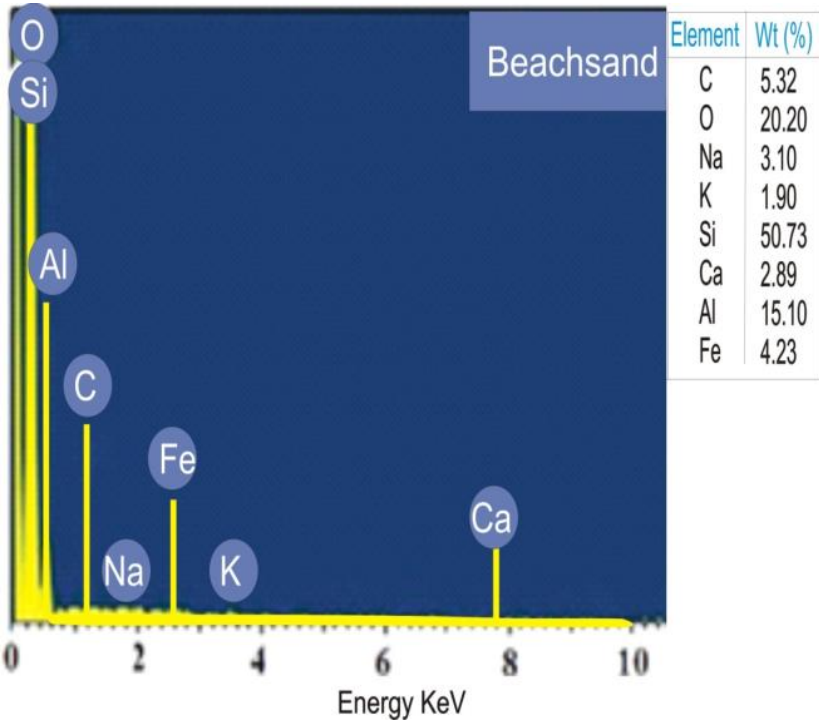

Fig. 6: EDX Analysis Showing Chemical Characterisation of the Beach Sand

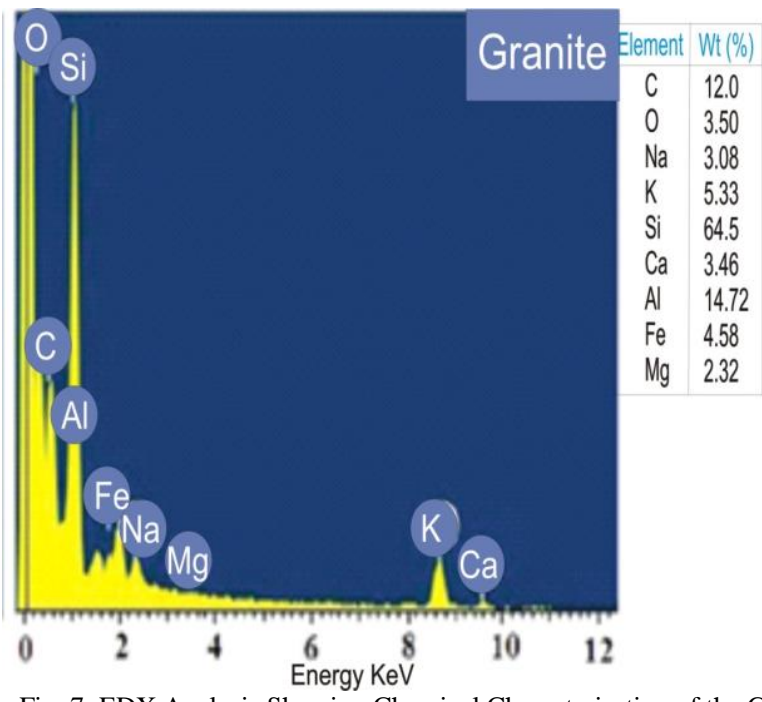

Fig. 7: EDX Analysis Showing Chemical Characterisation of the Granite 


\section{Conclusion}

The possession of Silica, Carbon, and several interconnected pores by the selected materials, viz. River Sand, Beach Sand and Granite are distinctive features of good water or wastewater adsorbents. Moreover, the absence or possession of minute quantity of Magnesium in the three selected materials makes them excellent adsorbents in water or wastewater treatment as they will not add to the hardness of the treated water. Finally, the possession of smaller pores by beach sand and river sand suggests that they will perform better as adsorbents than granite.

\section{References}

[1] Separation Processes, "Adsorbents", Retrieved from http://www.separationprocesses.com/Adsorption/AD_C hp01a.html May 20, 2018.

[2] S. A. Azeem, "Development of New Sorbents for Removal of Contaminants from Water",

Retrieved May 16, 2017 from http://www.suswatec.de/download/presentations/Abdel azeem.pdf, 2013.

[3] A. A. Adekunle, A. O. Familusi, A. A. Badejo, O. J. Adeosun and S. A. Arogundade, "Characterisation of Activated Charcoal, Sawdust Charcoal and Rice Husk Charcoal as Adsorbents in Water Treatment", Analecta Technica Szegedinensia, Vol. 14, No. 2, pp. 19-25, 2020.

[4] Geological Society London, "Aggregates for Use in Filter Media", Engineering Geology Special Publications, Vol. 17, pp. 291-298, 2001.

[5] O. S. Bello, I. A. Bello and K. A. Adegoke, "Adsorption of Dyes Using Different Types of Sand: A Review", South African Journal of Chemistry, Vol. 66, pp. 117-129, 2013.

[6] K. T. Parker, "Natural Materials Used for Water Filtration", Retrieved February 15, 2021 from https://sciencing.com/natural-materials-used-waterfiltration-5371122.html, 2017.

[7] B. Kavitha, and D. S. Thambavani, "Physico-Chemical Characterization of Riverbed Sand from Mullai Periyar, Tamilnadu" IOSR Journal of Applied Chemistry (IOSR-JAC), Vol. 7, No. 9, pp. 54-56, 2014.

[8] N. Jamil, N. Ahsan and U. Shafiq, "Lawrencepur Sand - A Highly Efficient Adsorbent for the Removal of $\mathrm{Cr}$ (VI) from Waste Water", Journal of the Chemical Society of Pakistan, Vol. 43, No. 32, pp. 81-88, 2012.

[9] G. M. Bhosale and V. D. Salkar, "Rehabilitation by Chemical Treatment for Sand Media of Rapid Sand Filtration units for Sangli City", IOSR Journal of Environmental Science, Toxicology and Food Technology (IOSR-JESTFT), Vol. 6, No. 5, pp. 32-37, 2013.

[10] EPA, "Water Health Series (Filtration Facts)", A Publication of Environmental Protection Agency, Retrieved January 6, 2017 from http://www.epa.gov/sites/production/files/201511/documents/2005_11_17_faq_fs_healthseries_filtrati on.pdf, 2005. 